\title{
United airways disease: therapeutic aspects
}

\author{
Giovanni Passalacqua, Giorgio Ciprandi, Giorgio Walter Canonica
}

During the past few years the global pathogenic view of respiratory allergy has changed. The link between rhinitis and asthma-that is, upper and lower airways - has been underlined by epidemiological and clinical studies. Taken together, these have led to the operative definition of "allergic rhinobronchitis" or, as we have proposed, "united airways disease (UAD)". In recent years more evidence has been provided of the frequent co-existence of rhinitis and asthma, the possible role of upper respiratory infections, and the importance of paranasal sinus infections. These relationships are particularly notable in children. Detailed knowledge of the mechanisms sustaining allergic inflammation in the respiratory tract allows a greater understanding of the functional relationships between the upper and lower sections of the tract. In this respect it is logical to assume that allergy is not a disease confined to a specific target organ, but rather a disorder of the whole respiratory tract which has a broad spectrum of clinical manifestations. The concept of "united airways disease" also has therapeutic implications.

\section{Epidemiological evidence}

Early epidemiological studies described the association between allergic rhinitis and asthma. One of the earliest observations on a large sample assessed the effects of specific immunotherapy. ${ }^{2}$ This association has been further investigated and substantiated in more recent studies. ${ }^{3}$ It has become clear that the association between rhinitis and asthma is very strong, ${ }^{4-7}$ that bronchial hyperresponsiveness is frequent in patients with rhinitis, ${ }^{8}$ and that rhinitis itself is a primary risk factor for subsequent asthma. ${ }^{9-11}$ Moreover, it has recently been shown that, when a rigorous diagnosis is made, the prevalence of rhinitis in asthmatic patients approaches $100 \%{ }^{12}$ All observations suggest that progression of the disease occurs from the upper to the lower respiratory tract.

Immunological and pathogenic aspects The respiratory tract can be considered as a unique morphofunctional entity covered by ciliated epithelium and mucinous glands and served by an extensive vasculature and neural innervation. The neural innervation is a common feature of the two compartments. Moreover, the respiratory mucosa is rich in mast cells and the lymphoid tissue which constitutes the bronchial (mucosal) associated lymphoid tissue (BALT or MALT). The upper respiratory tract functions as a physical filter, heat exchanger, and humidifier for inhaled air. A failure of any of these functions usually results in an alteration in the homeostasis of the lower respiratory airways. The only relevant functional difference between the two compartments is the presence of bronchial smooth muscle.

When an allergic reaction occurs, an early phase mediated by histamine takes place within minutes. This reaction is followed by a complex network of inflammatory phenomena involving $\mathrm{T}$ lymphocytes, cytokines, and adhesion molecules. The adhesion machinery, in particular, seems to be crucial for the recruitment of inflammatory cells at the target organ. During the early phase specific adhesion molecules are expressed on the surface of the endothelium and epithelium, thus favouring extravasation and epithelial infiltration of inflammatory cells. Interestingly, a weak inflammatory infiltration is present at the mucosal level even in the absence of symptoms when a subliminal exposure to the allergen persists. This is called "minimal persistent inflammation (MPI)" and has been demonstrated in both mite ${ }^{13}$ and pollen ${ }^{14}$ induced rhinitis, as well as in asthma. The MPI also involves a weak and persistent expression of the CD54 (ICAM-1) molecule which is the major receptor for human rhinoviruses. ${ }^{15}$ This is important in view of the fact that asthma exacerbations are closely related to upper respiratory viral infections in children. ${ }^{16}{ }^{17}$

The following mechanisms have been proposed to explain the effect of rhinitis on asthma: (a) the rhinobronchial adrenergic reflex; (b) the failure of the heater/humidifier system; and (c) the humoral activation of bone marrow precursors. ${ }^{18}$

\section{Therapeutic implications}

Two main observations are of relevance from a therapeutic perspective: (1) the unity of the respiratory airways and the influence exerted by the nose on the bronchi and (2) the fact that both symptoms and allergic inflammation should be targets for treatment. Indeed, there is some evidence to suggest that optimal control of rhinitis has a beneficial effect on asthma in terms of reduction of bronchial responsiveness during natural exposure to the offending allergens. ${ }^{1920}$ Moreover, in a double blind, double dummy study it was observed that intranasal beclomethasone was more effective then inhaled beclomethasone in reducing carbachol induced bronchoconstriction in patients with asthma. ${ }^{21}$

On the other hand, the existence of a persistent inflammation suggests the need for continuous rather than on demand treatment with antiallergic drugs. ${ }^{22}$ This concept has been shown experimentally with several second generation antihistamines. Continuous use was found to be better for controlling symptoms, 
allergic inflammation, ${ }^{23}{ }^{24}$ and the occurrence of upper respiratory infections in children. ${ }^{25}$ These findings, usually seen in small groups of subjects, were observed in the large ETAC study population in which continuous antihistamine treatment was shown to prevent the onset of asthma. ${ }^{26}$ One of the new clues to the treatment of united airways disease is the evidence of a synergistic effect of drugs used in both rhinitis and asthma-for example, antileukotrienes added to antihistamines ${ }^{27}$ or inhaled corticosteroids, or $\beta_{2}$ agonists added to antihistamines. This aspect is relevant since it would allow treatment to be harmonised, possibly reducing the dosage of each drug. Ultimately, this may result in better control of the disease(s) and fewer side effects.

\section{Conclusions}

A Galilean procedure applied to united airways disease implies clinical observation, the formulation of a hypothesis, and the validation of the hypothesis by controlled and reproducible experiments. At present epidemiological observations suggest that the hypothesis of united airways disease is tenable, and there is an increasing amount of direct and indirect experimental evidence to support this hypothesis. United airways disease is beginning to be considered as an evidence based entity and a new therapeutic approach to the management of respiratory allergy is therefore possible.

This work was partially supported by ARMIA (Associazion Ricerca Malattie Immunologiche e Allergiche) and MURST (Ministry of University, Scientific and Technologic Research)

1 Simons FER. Allergic rhinobronchitis: the asthma-allergic rhinitis link. F Allergy Clin Immunol 1994;104:534-40.

2 Johnstone D, Dutton A. The value of hyposensitization therapy for bronchial asthma in children: a 14 year study. Pediatrics 1968;42:793-7.

3 Annesi-Maesano I. Epidemiological evidence of the occurrence of rhinitis and sinusitis in asthma. Allergy 1999. 54(Suppl 57):7-13.

4 Scadding $\mathrm{G}$. The coexistence of upper and lower respiratory airways diseases. Respir Dis Pract 1994;11:18-20.

5 Ciprandi G, Vizzaccaro A, Cirillo I, et al. Increase of asthma and allergic rhinitis in young Italian men. Int Arch Allergy Immunol 1996;111:277-83.

6 Spector SL. Overview of comorbid association of allergic rhinitis. F Allergy Clin Immunol 1997;99:S773-80.

7 Corren J. The impact of allergic rhinitis on bronchial asthma. F Allergy Clin Immunol 1998;101:s352-6.
8 Brannan SS, Barrows AA, DeCotiis BA, et al. Airways hyperresponsiveness in allergic rhinitis. A risk factor for hyperresponsiveness in allerg

9 Settipane G, Settipane RJ, Hagy GW. Long term risk factors for developing asthma amd allergic rhinitis: a 23 year follow up study of college students. Allergy Proc 1994;15:21-5.

10 The International Study of Asthma and Allergies in Childhood (ISAAC). Worldwide variation in prevalence of symptoms of asthma, allergic rhinoconjunctivitis and atopic eczema. Lancet 1998;351:1225-32.

11 Gergen PJ, Turkeltaub PC. The association of individual allergen reactivity with respiratory disease in a national sample. Data from the Second National Health and Nutrition Examination Survey, 1976-80 (NHANES). J Allergy Clin Immunol 1992;90:579-88.

12 Kapsali T, Horowitz E, Togias A. Rhinitis is ubiquitous in allergic asthmatics. F Allergy Clin Immunol 1999;99:S138.

13 Ciprandi G, Buscaglia S, Pesce GP, et al. Minimal persistent inflammation is present at mucosal level in asymptomatic rhinitic patients with allergy due to mites. F Allergy Clin Immunol 1995;96:971-9.

14 Ricca V, Landi M, Ferrero E, et al. Minimal persistent inflammation is also present in patients with pollen allergy. 7 Allergy Clin Immunol 2000;105:54-63.

15 Greve JM, Davis G, Meyer AM, et al. The major human rhinovirus receptor is ICAM-1. Cell 1989;56:839.

16 Johnston SL, Pattermore PK, Sanderson G, et al. The relationship between upper respiratory infections and hospital admissions for asthma: a time-trend analysis. Am $\mathcal{F}$ Respir Crit Care Med 1996;154:654-60.

17 Johnston SL, Pattermore PK, Sanderson G, et al. A longitudinal study on the role of viral infections in exhacerbations of asthma in school children in the community. BMF 1995; 310:1225-9.

18 Denburgh J. The nose, the lung and the bone marrow in allergic inflammation. Allergy 1999;54:73-80.

19 Watson WT, Becker AB, Simons FER. Treatment of allergic rhinitis with intranasal corticosteroids in patients with mild asthma: effect on lower airway responsiveness. F Allergy Clin Immunol 1993;91:97-101.

20 Corren J, Adinoff AD, Buckmeier AD, et al. Nasal beclometasone prevents the seasonal increase in bronchial responsiveness in patients with allergic rhinitis and asthma. $\mathcal{F}$ Allergy Clin Immunol 1992;90:250-6.

21 Aubier M, Levy J, Clerici C, et al. Different effects of nasal and bronchial glucocorticosteroids administration on bronchial responisveness in patients with rhinitis. Am Rev Respir Dis 1992;146:122-6.

22 Ciprandi G, Passalacqua G, Canonica GW. Effects of $H_{1}$ antihistamines on adhesion molecules: a possible rationale for longterm treatment. Clin Exp Allergy 1999;29:49-53.

23 Ciprandi G, Ricca V, Passalacqua G, et al. Seasonal rhinitis and azelastine: long or short term treatment? F Allergy Clin Immunol 1997;99:301-7.

24 Ciprandi G, Passalacqua G, Mincarini M, et al. Continuous versus on demand treatment with cetirizine for allergic rhinitis. Ann Allergy Asthma Immunol 1997;79:507-55.

25 Ciprandi G, Ricca V, Tosca MA, et al. Continuous antihistamine treatment controls allergic inflammation and reduces respiratory morbidity in children with mite allergy. Allergy 1999;54:358-65.

26 ETAC Study Group. Allergic factors associated with the development of asthma and the influence of cetirizine in a double blind randomized placebo controlled trial. Pediatr Allergy 1998;3:116-24.

27 Meltzer EO. Role for cysteinyl leukotrienes receptor antagonist therapy in asthma and their potential role in allergic rhinitis based on the concept of one linked airways disease. Ann Allergy Asthma Immunol 1999;84:176-87. 